\title{
Short-term association between air pollution and emergency room visits for asthma in Barcelona
}

\author{
J Castellsague, J Sunyer, M Sáez, J M Antó
}

\begin{abstract}
Background - Several studies have assessed the association between urban air pollutants and hospital admissions or emergency room visits for asthma with inconsistent results. The objective of this study was to assess the relation between levels of black smoke, sulphur dioxide, nitrogen dioxide, and ozone and adult emergency room visits for asthma in Barcelona, Spain during the five year period 1985-9. Methods - The daily number of emergency room visits for asthma was obtained from a register of respiratory emergencies designed to study the asthma outbreaks occurring in Barcelona. The association between asthma visits and levels of pollutants was assessed separately for summers and winters with Poisson regression models controlling for meteorological and time related variables.
\end{abstract}

Results - Black smoke was associated with asthma visits in summer but not in winter. The relative risk (RR) of asthma visits for a $25 \mu \mathrm{g} / \mathrm{m}^{3}$ increase of current day concentrations of black smoke was $1.082(95 \%$ CI $1 \cdot 011$ to $1 \cdot 157)$. The mean current and previous three day levels of black smoke led to a stronger association $(R R=1 \cdot 114$ $(95 \%$ CI $1 \cdot 010$ to $1 \cdot 160)$. In addition, nitrogen dioxide was associated with asthma visits in both summer $(R R=1 \cdot 045,95 \% C I$ 1.009 to 1.081$)$ and winter $(R R=1.056,95 \%$ CI 1.011 to 1.104). These associations were slightly higher for the previous day's level of nitrogen dioxide. No associations were found for sulphur dioxide or for ozone.

Conclusions - This study provides further evidence of the effect of particulate pollution on asthma, and it suggests that nitrogen dioxide may have a role in the exacerbation of bronchial asthma in adults.

(Thorax 1995;50:1051-1056)

Keywords: asthma, air pollution, nitrogen dioxide, emergency room admissions.

In recent years the prevalence of bronchial asthma has been increasing in many countries and the reasons for such increase are still uncertain. ${ }^{1}$ The possible role of chemical air pollution on asthma has been widely investigated in experimental and epidemiological studies. Both types of studies have shown that current levels of urban air pollution can exacerbate respiratory symptoms in subjects with bron- chial asthma. In addition, there is some evidence that air pollutants may enhance the response of the airways to allergens.

Thus, in controlled chamber studies asthmatic patients have shown higher bronchial reactivity than healthy subjects after exposure to sulphur dioxide. ${ }^{2}$ A comparable, although less consistent, effect has been found for nitrogen dioxide ${ }^{34}$ and ozone. ${ }^{5}$ Similarly, panel studies of asthmatic subjects have related urban levels of particulates, sulphur dioxide, and photochemical pollution with increased reports of symptoms and asthma attacks, ${ }^{6-8}$ greater bronchodilator use, and decreased pulmonary function. ${ }^{89}$ However, most of these studies have included a limited number of asthmatic subjects and the occurrence of attacks has usually been based on self reporting without clinical validation. On the other hand, epidemiological studies in general populations have shown positive associations between air pollution levels and the incidence and duration of respiratory symptoms in healthy subjects. ${ }^{9-12}$

Emergency room visits for asthma are an indicator of severe asthma which allows the study of the temporal relation between air pollution levels and asthma exacerbation. Although several studies have assessed this relationship, the results are not totally consistent. Some studies have found positive associations between visits for asthma and levels of particulates, ${ }^{13-17}$ sulphur dioxide, ${ }^{131617}$ and ozone. ${ }^{16}$ However, negative results have also been reported for sulphur dioxide, ${ }^{14} 18$ nitrogen dioxide, ${ }^{1617}$ and ozone. ${ }^{1417}$

The objective of the present study was to assess the relation between urban air pollution levels and emergency room visits for asthma in Barcelona from 1985 to 1989. Barcelona is one of the most densely populated cities of Europe whose primary sources of air pollution are those associated with vehicular traffic. Since 1985 air pollution levels have been regularly monitored with a local network of automatic and manual stations, providing daily data on several air pollutants. Likewise, daily information on emergency room visits for asthma was available from a reliable register of respiratory emergencies designed to study the asthma outbreaks caused by inhalation of soybean dust. ${ }^{1920}$

\section{Methods}

SUBJECTS AND DATA COLLECTION

The number of emergency room visits daily for asthma of residents in Barcelona over 14 years of age was obtained from a register of hospital 
respiratory emergencies, which included the four largest hospitals in the city and covered about $80 \%$ of all asthma emergency visits. ${ }^{20}$ The register was active during a five year period. It was set up in 1985 for the study of the asthma epidemics occurring in Barcelona and was cancelled in December 1989, two years after the identification of the cause of the epidemics.

An admission for asthma was defined as an emergency room visit during which any asthmarelated diagnosis was recorded. A panel of respiratory physicians developed a list of equivalent terms used by clinicians in the diagnosis of asthma which included: asthma, severe asthma attack, asthmatic bronchitis, spastic bronchitis, bronchial hyperreactivity, asthmatic status, wheezing, and bronchospasm. An alternative list for chronic obstructive pulmonary disease (COPD) was also used and all visits recorded under this category were excluded. Clinical records of all the emergency room visits were reviewed by trained physicians. The reliability of the register was assessed in a repeatability study. ${ }^{20}$ The agreement in classifying asthma versus non-asthma was excellent (kappa $=0.81$ ), whereas the corresponding value in classifying asthma versus COPD was even higher $(\mathrm{kappa}=0.91){ }^{20}$

Daily data on air pollution were obtained from the city monitoring network which consisted of 15 manual samplers and three automatic stations. Data included 24 hour average sulphur dioxide (conductivity method) and black smoke (British smoke filter technique) levels, and one hour maximum values of nitrogen dioxide (chemiluminescence) and ozone (chemiluminescence). The 24 hour and one hour maximum levels were estimated as the arithmetic mean of all the manual and automatic measurements, respectively. We assumed that on a given day all the population was exposed to the same average levels of pollutants. Since a high proportion of daily nitrogen dioxide and ozone values from the two automatic stations during the year 1985 was missing, this year was excluded from the analysis. Daily meteorological data were collected from a weather station located at the city airport. Additional details on air pollution and meteorological data collection have been published elsewhere. ${ }^{2122}$

\section{DATA ANALYSIS}

The analysis was performed separately for the winter (1 January to $31 \mathrm{March}$ ) and summer (1 July to 30 September) seasons. Since the sources, composition, and levels of air pollutants vary among seasons, this approach permits a better interpretation of the effect of air pollutants. In addition, stratification by season results in greater homogeneity of potential confounders or effect modifiers such as weather conditions, concentration of ambient allergens, respiratory viral infections, or patients' activity patterns, allowing a more adequate control of confounding. The analysis in the winter is of interest because the highest levels of black smoke and sulphur dioxide occur in this season, whereas in summer ozone and nitrogen dioxide are the predominant air pollutants. On the other hand, viral respiratory disease and low temperatures are uncommon in the summer. Spring and autumn were excluded from this analysis because air pollution effects are more likely to be confounded by other variables in these seasons. Thus, the spring is characterised by high pollen concentrations, and the autumn coincides with a rise in influenza and viral infections.

The daily counts of asthma visits in a large population can be considered a rare event which is more properly modelled as a Poisson process. In this series, asthma visits were not normally distributed either in winter or in summer, and the variances were similar to the means, especially in the summer (mean $=2 \cdot 7$, variance $=3 \cdot 0$ ). Thus, the association between asthma visits and air pollutants was assessed using Poisson regression models. Since misclassification between asthma and COPD is more likely to occur in the elderly, asthma visits of patients over 65 years were excluded from the analysis.

\section{TIME TRENDS AND WEATHER CONDITIONS}

Admission rates for asthma may be related to factors other than pollutants that fluctuate with time. The first step in the analysis was to assess the effect of time-related variables. Long time trends were tested with continuous linear and quadratic terms, and shorter trends with indicator variables for each study year and month. Finally, day of the week variability was examined with indicator variables for each week day.

The association between asthma visits and weather variables was assessed in the models including the significant time-related variables. The weather variables studied were temperature (daily minimum, maximum, and mean), relative humidity, and dew point temperature. Continuous as well as categorical values of these variables were considered, thus allowing for non-linear associations. Current values and those up to five previous days were examined for each variable. Cumulative exposures were also tested with the mean values of several previous consecutive days. Since bronchial reactivity of patients with asthma can be associated with cold and dry air, ${ }^{23}$ and with hot and humid air, ${ }^{24}$ both types of conditions were assessed with additional indicator terms. Days were classified as cold, dry, hot, and humid according to their 10th and 90th seasonal percentiles of temperature and relative humidity.

\section{AIR POLLUTANTS}

The association between the daily number of emergency room visits for asthma and air pollutant levels was assessed in the models including the significant weather and time-related variables. Given the strong collinearity among some pollutants (correlation coefficients between 0.32 and 0.73 , excluding ozone) each one was analysed separately. Since emergency 

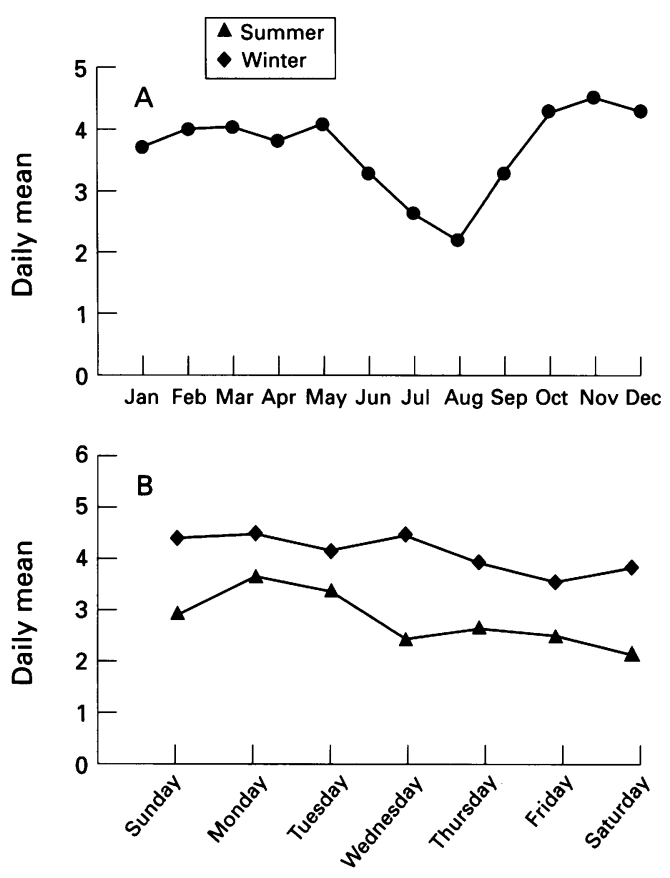

Figure 1 Daily mean of admissions to emergency room for asthma by $(A)$ month and $(B)$ day of the week in Barcelona, Spain, 1985-9.

room visits for asthma may depend on the previous days' pollution levels, single lagged (up to five days) as well as mean lagged values of pollutants were examined. Air pollutant levels were first considered as continuous, and the relative risk of asthma visits was computed for an increase of $25 \mu \mathrm{g} / \mathrm{m}^{3}$ for each air pollutant in a given day. To assess the associations further, the quartiles of air pollutant levels were introduced as categorical variables in the adjusted regression models, and the relative risk of asthma visits was estimated for each quartile in respect to the lowest one. In addition, twoway interactions between air pollutants were assessed in the final Poisson models controlling for the rest of the variables. In order to decrease collinearity, interaction terms were assessed with the levels of one of the pollutants being considered as continuous and those of the other pollutant as categorical (tertiles).

Effect of levels of soybean dust on asthma visits Between 1981 and 1987 several outbreaks of asthma caused by inhalation of soybean dust occurred in Barcelona. ${ }^{19}$ In consequence, part of the study period (January 1985 to October 1987) was influenced by the occasional presence of soybean dust in the ambient air of the city. The effect of soybean dust on the number of asthma visits was controlled for in the regression analysis with an indicator variable for days with soybean unloading during the epidemic period. In addition, epidemic days (four in winter and 10 in summer) were excluded from the analysis in order to avoid residual confounding.

\section{Autocorrelation and overdispersion}

To account for autocorrelation, the adjusted regression models were re-estimated using autoregressive Poisson models. ${ }^{25}$ In addition, overdispersion was estimated from the residual $\chi^{2}$ using the method described by McCullagh and Nelder ${ }^{26}$ and incorporated in the estimation of the regression coefficients.

\section{Results}

The distribution of daily emergency room visits for asthma by month and day of the week for the period 1985-9 are presented in fig 1. The number of asthma visits was lower in the warm period from June to September, and uniformly higher in the remaining months. By day of the week the distribution during the winter was practically constant, whereas in summer Mondays showed the highest visit rates. The distributions of asthma visits, air pollutants, and weather variables for both summer and winter are shown in table 1 . The daily means of asthma visits and the levels of sulphur dioxide and black smoke were higher in winter than in summer. Nitrogen dioxide levels were similar in both seasons, and ozone showed higher concentrations in summer than in winter.

In the crude analysis asthma visits increased across quartiles of black smoke and nitrogen dioxide in summer (table 2). A positive but less consistent increase was also found for sulphur dioxide in summer, and for nitrogen dioxide and ozone in winter.

In Poisson regression analysis no long term trends were found in summer, whereas in winter a linear and a quadratic term for time trend were highly significant $(p<0.001)$. Year was not associated with asthma visits either in summer or in winter. Indicator variables for month and day of the week were statistically significant in both seasons $(\mathrm{p}<0 \cdot 05)$.

Table 1 Distribution of daily emergency room admissions, air pollutants $\left(\mu \mathrm{g} / \mathrm{m}^{3}\right)$ and meteorology by season in Barcelona, Spain, 1985-9

\begin{tabular}{|c|c|c|c|c|c|c|c|c|c|c|c|c|}
\hline & \multicolumn{6}{|c|}{ Summer } & \multicolumn{6}{|c|}{ Winter } \\
\hline & \multirow[t]{2}{*}{ No. } & \multicolumn{4}{|c|}{ Percentiles } & \multirow[t]{2}{*}{ Mean } & \multirow[t]{2}{*}{ No. } & \multicolumn{4}{|c|}{ Percentiles } & \multirow[t]{2}{*}{ Mean } \\
\hline & & 25 & 50 & 75 & 95 & & & 25 & 50 & 75 & 95 & \\
\hline Asthma admissions & 460 & 1 & 2 & 4 & 6 & $2 \cdot 7$ & 452 & 2 & 4 & 5 & 8 & 3.9 \\
\hline Sulphur dioxide & 460 & 25 & 36 & 54 & 82 & $40 \cdot 8$ & 452 & $3 \overline{6}$ & 49 & 67 & 94 & $52 \cdot 0$ \\
\hline Black smoke & 460 & 31 & 46 & 63 & 92 & $48 \cdot 2$ & 452 & 45 & 62 & 84 & 132 & $68 \cdot 0$ \\
\hline Nitrogen dioxide* & 321 & 73 & 97 & 121 & 183 & $104 \cdot 0$ & 361 & 82 & 100 & 119 & 153 & $100 \cdot 8$ \\
\hline Ozone* & 356 & 60 & 83 & 103 & 139 & $84 \cdot 3$ & 361 & 37 & 55 & 69 & 103 & $56 \cdot 6$ \\
\hline Minimum temperature $\left({ }^{\circ} \mathrm{C}\right)$ & 460 & 17 & 19 & 20 & 22 & $18 \cdot 3$ & 452 & $2 \cdot 8$ & 5 & 7 & 10 & 4.8 \\
\hline Relative humidity (\%) & 460 & 72 & 77 & 81 & 85 & $76 \cdot 0$ & 452 & 68 & 76 & 82 & 91 & $74 \cdot 0$ \\
\hline
\end{tabular}

* Data available for the period 1986-9. 
Table 2 Daily mean of admissions to emergency room for asthma for each quartile of air pollutants by season, Barcelona, Spain, 1985-9

\begin{tabular}{|c|c|c|c|c|c|c|c|c|}
\hline & \multicolumn{4}{|c|}{ Summer (quartiles) } & \multicolumn{4}{|c|}{ Winter (quartiles) } \\
\hline & 1 & 2 & 3 & 4 & 1 & 2 & 3 & 4 \\
\hline $\begin{array}{l}\text { Sulphur dioxide } \\
\text { Black smoke } \\
\text { Nitrogen dioxide } \\
\text { Ozone }\end{array}$ & $\begin{array}{l}2 \cdot 48 \\
2 \cdot 32 \\
2 \cdot 29 \\
2 \cdot 67\end{array}$ & $\begin{array}{l}2 \cdot 32 \\
2 \cdot 39 \\
2 \cdot 71 \\
2 \cdot 70\end{array}$ & $\begin{array}{l}2 \cdot 77 \\
2 \cdot 86 \\
2 \cdot 75 \\
2 \cdot 52\end{array}$ & $\begin{array}{l}3 \cdot 15 \\
3 \cdot 14 \\
2 \cdot 88 \\
2 \cdot 74\end{array}$ & $\begin{array}{l}3.96 \\
4 \cdot 16 \\
3.57 \\
3.54\end{array}$ & $\begin{array}{l}3 \cdot 56 \\
3 \cdot 35 \\
3 \cdot 88 \\
3 \cdot 73\end{array}$ & $\begin{array}{l}4 \cdot 07 \\
4 \cdot 03 \\
3 \cdot 55 \\
4 \cdot 25\end{array}$ & $\begin{array}{l}4 \cdot 03 \\
4 \cdot 08 \\
4 \cdot 43 \\
3 \cdot 88\end{array}$ \\
\hline
\end{tabular}

Meteorological variables, particularly temperature, are probably the most important confounding factors in this type of air pollution study. The most significant weather predictors of asthma visits in the summer were the minimum temperature and relative humidity during the previous two days. Daily visits for asthma declined by $5 \%$ for each ${ }^{\circ} \mathrm{C}$ increase of minimum temperature $(R R=0.95,95 \%$ CI 0.93 to 0.98 ) and increased by $1 \%$ for each percentage unit of relative humidity $(R R=1.01,95 \% \mathrm{CI}$ 1.003 to 1.020 ). In winter the best weather predictors of asthma visits were the previous day's values for both minimum temperature $(R R=0.98,95 \%$ CI 0.97 to 0.99$)$ and relative humidity ( $R R=1.002,95 \%$ CI 1.000 to 1.006). No significant associations were found for cold/dry and hot/humid days either in summer or in winter, and categorical transformations of the weather variables did not improve the fit of the models.

After adjusting for weather and time-related variables, current day levels of black smoke were significantly associated with emergency room visits for asthma in summer (table 3 ). Asthma visits increased by $8 \cdot 2 \%$ for each $25 \mu \mathrm{g}$ / $\mathrm{m}^{3}$ increase in levels of black smoke. The mean of the current and previous three days' concentrations of black smoke led to a stronger association with asthma visits than current day values $(R R=1 \cdot 114,95 \%$ CI $1 \cdot 010$ to $1 \cdot 160)$. In winter the magnitude of the associations for current and lagged levels of black smoke were lower and statistically not significant. In addition, a positive and significant association was found for nitrogen dioxide in both summer and winter (table 3). The increase in asthma visits for a $25 \mu \mathrm{g} / \mathrm{m}^{3}$ increase of current day levels of nitrogen dioxide was $4.5 \%$ in summer and $5.6 \%$ in winter. The associations were slightly stronger with a cumulative measure of nitrogen dioxide. In summer the relative risk for the mean of the current and previous five days' values was 1.071 (95\% CI 1.010 to

Table 3 Adjusted association between emergency room admissions for asthma and air pollutant levels by season, Barcelona, Spain, 1985-9

\begin{tabular}{|c|c|c|c|c|c|c|}
\hline & \multicolumn{3}{|l|}{ Summer* } & \multicolumn{3}{|l|}{ Winter** } \\
\hline & $\begin{array}{l}\text { Relative } \\
\text { risk } \neq\end{array}$ & $\begin{array}{l}\text { 95\% confidence } \\
\text { interval }\end{array}$ & $p$ & $\begin{array}{l}\text { Relative } \\
\text { risk } \neq\end{array}$ & $\begin{array}{l}\text { 95\% confidence } \\
\text { interval }\end{array}$ & $p$ \\
\hline Sulphur dioxide & 1.052 & 0.980 to 1.129 & $0 \cdot 15$ & $1 \cdot 020$ & 0.960 to 1.084 & 0.5 \\
\hline \multirow{2}{*}{ Black smoke } & 1.082 & 1.011 to 1.157 & 0.02 & 1.023 & 0.980 to 1.065 & $0 \cdot 3$ \\
\hline & $1 \cdot 114 \S$ & $1 \cdot 010$ to $1 \cdot 160$ & 0.01 & - & - & - \\
\hline \multirow[t]{2}{*}{ Nitrogen dioxide } & $1.045^{\circ}$ & 1.009 to 1.081 & 0.01 & $1 \cdot 056$ & 1.011 to 1.104 & 0.02 \\
\hline & $\begin{array}{l}1.071 \S \\
0.991\end{array}$ & $\begin{array}{l}1.010 \text { to } 1.130 \\
0.939 \text { to } 1.045\end{array}$ & $\begin{array}{l}0.02 \\
0.70\end{array}$ & $\begin{array}{l}1.072 \S \\
1.055\end{array}$ & $\begin{array}{l}1.010 \text { to } 1.137 \\
0.998 \text { to } 1.116\end{array}$ & $\begin{array}{l}0.02 \\
0.1\end{array}$ \\
\hline
\end{tabular}

* Adjusted for two days lag of minimum temperature and relative humidity, month, day of the week, and soybean unloading.

** Adjusted for one day lag of minimum temperature and relative humidity, time trends, month, day of the week, and soybean unloading.

$\ddagger$ Relative risk of asthma admissions for each $25 \mu \mathrm{g} / \mathrm{m}^{3}$ increase in air pollutant.

$\S$ Relative risks for lagged exposures.

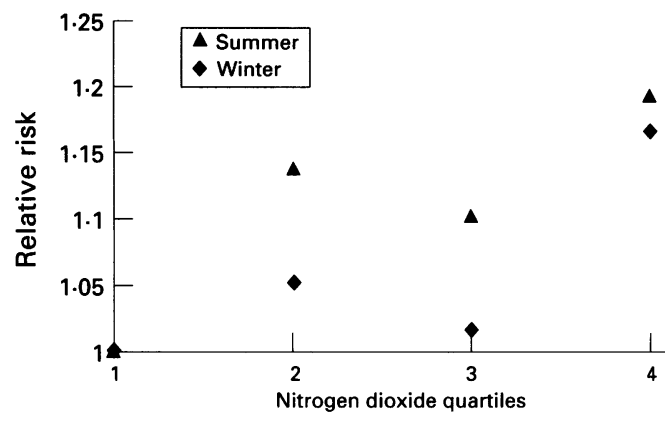

Figure 2 Adjusted relative risks of emergency room admissions for asthma by quartiles of nitrogen dioxide plotted against mean nitrogen dioxide levels of each quartile stratified by season, Barcelona, Spain, 1985-9.

$1 \cdot 130)$. In winter the relative risk was 1.072 ( $95 \%$ CI 1.010 to $1 \cdot 137$ ) for the mean of the current level and that of the previous two days.

The plot of the adjusted relative risks of asthma visits for each quartile of nitrogen dioxide showed increased risks in each quartile, although a consistent linear trend was not evident (fig 2). However, an increased risk in the second quartile was apparent in both summer and winter, suggesting a low, if any, threshold level. Finally, sulphur dioxide in both seasons, and ozone in winter, showed positive although not statistically significant associations with asthma visits. None of the interactions between air pollutants was significant in summer or winter. Controlling for autocorrelation and overdispersion led to nearly identical associations and standard errors in both seasons. Autoregressive terms up to the fourth order were not significant either in summer or in winter.

\section{Discussion}

This study showed a small but significant association of particulates and nitrogen dioxide with emergency room visits due to asthma in Barcelona. These associations were independent of the effect of temperature, humidity, and time trends. In contrast, no significant associations were found for sulphur dioxide or for ozone.

Black smoke in summer showed the strongest association with asthma visits which increased by $11 \%$ for a $25 \mu \mathrm{g} / \mathrm{m}^{3}$ increase in the level of black smoke. Several studies have reported similar positive associations. Black smoke has been related to hospital admissions for asthma in a recent study in Birmingham, ${ }^{13}$ and Bates and colleagues have reported positive correlations between sulphate particulates in Ontario and Vancouver. ${ }^{1617}$ The strength of the association found in the present study is consistent with that reported by Schwartz et al in Seattle for inhalable particles $\left(\mathbf{P M}_{10}\right) \cdot{ }^{14}$ Using Poisson regression and controlling for several variables these authors reported a $12 \%$ increase in asthma visits for an increase of $30 \mu \mathrm{g} / \mathrm{m}^{3}$ of $\mathrm{PM}_{10}$. This change was observed for the mean of the previous four days' concentrations of $\mathrm{PM}_{10}$, which is a similar lagged effect to that 
observed in our study. A positive association with $\mathrm{PM}_{10}$ has also been reported by Pope in the Utah Valley where hospital admission rates for asthma increased significantly during the periods when the local steel mill, the main source of particles, was operating. ${ }^{15}$

In spite of higher levels of black smoke during the winter, the association of this pollutant with asthma visits was stronger in summer. This is consistent with the results from Ontario where sulphate particulates were related to asthma admissions in summer but not in winter. ${ }^{16}$ In Vancouver a similar association was observed in all age groups in the summer, but in the winter it was restricted to patients over 61 years. ${ }^{17}$ In contrast, in the Birmingham study the effect of black smoke on asthma admissions was stronger in winter than in summer. ${ }^{13}$

Chemical analysis of large $(>7.2 \mu \mathrm{m})$ and small $(<0.5 \mu \mathrm{m})$ particle fractions of aerosol samples in Barcelona have shown seasonal variations in the composition and size of particulates. ${ }^{27} 28$ Since the seasonal distribution of the type and concentrations of particulates probably varies among geographical areas, seasonal differences in the effect of particulate pollution in different studies is likely to occur.

A limitation of this study is that black smoke is a crude indicative measure of inhalable particulate pollution. The British smoke filter technique measures the blackness of the sampled particles. Although fine particles with an aerodynamic diameter of less than $5 \mu \mathrm{m}$ tend to be black, particles derived from vehicle exhausts are less black and are not accurately measured with the smoke filter technique. However, a better indicator of inhalable particles such as $\mathrm{PM}_{10}$, which measures the mass of all particulates with an aerodynamic diameter of less than $10 \mu \mathrm{m}$, is not available in Barcelona.

Another finding of our study was the positive association between nitrogen dioxide levels and asthma visits. An increase in asthma visits of approximately $7 \%$ was observed in the two seasons considered. These results contrast with those of Bates et al in Ontario ${ }^{16}$ and Vancouver ${ }^{17}$ where no associations between nitrogen dioxide levels and hospital and emergency room admissions for asthma were found either in summer or in winter, although in both areas nitrogen dioxide levels were lower (daily mean of approximately $80 \mu \mathrm{g} / \mathrm{m}^{3}$ ) than those of Barcelona. Contradictory results have also been reported in epidemiological studies conducted in specific populations. Nitrogen dioxide levels have been related to the duration of respiratory symptoms in a random sample of children ${ }^{10}$ and to the incidence of episodes of phlegm, sore throat, and eye irritation in healthy student nurses. ${ }^{11}$ Other studies examining symptomatic and asymptomatic children have not found significant associations between nitrogen dioxide levels and either respiratory symptoms or pulmonary function. ${ }^{29}{ }^{30}$ Negative results have also been reported for the duration of respiratory symptoms in healthy adults. ${ }^{12}$ For nitrogen dioxide a number of experimentally controlled studies have been conducted. Small groups of subjects with asthma have been experimentally exposed to inhalation of a wide range of nitrogen dioxide concentrations $\left(190-7520 \mu \mathrm{g} / \mathrm{m}^{3}\right)$ and both negative $\mathrm{e}^{31-33}$ and positive ${ }^{343435}$ results have been obtained across the whole range of doses. The lowest level of nitrogen dioxide associated with functional impairment in asthma subjects in the experimental setting has been $190 \mu \mathrm{g} / \mathrm{m}^{3},{ }^{3}$ which corresponds approximately with the peak levels observed in Barcelona. The reasons for such contradictory results in both epidemiological and experimental studies remain unclear, but it is unlikely to be due to methodological weaknesses since a wide range of methods has been used in both types of studies. Although pathological effects of exposure to nitrogen dioxide have been documented both in in vitro human ${ }^{36}$ and animal ${ }^{37}$ models, the specific mechanisms linking these effects to asthma have not been yet established. Recent experimental studies have suggested that nitrogen dioxide alone, ${ }^{38}$ or in combination with sulphur dioxide, ${ }^{39}$ may enhance the bronchial response to inhaled allergens.

In our study neither sulphur dioxide nor ozone were significantly associated with asthma visits. The findings on sulphur dioxide are consistent with the results of Goldstein et al in New York ${ }^{18}$ where no association was observed at levels considerably higher than those of Barcelona. Similarly, in the Seattle study sulphur dioxide was not related with emergency room visits for asthma, although in this city the station monitoring sulphur dioxide levels was not representative of the population exposure. ${ }^{14}$ In contrast, some studies have reported significant associations between sulphur dioxide levels and admissions or emergencies for asthma. Levels of sulphur dioxide have been related to hospital admissions for asthma in Ontario in the summer but not in the winter, ${ }^{16}$ and in both seasons in Vancouver. ${ }^{17}$ Significant associations have also been reported in winter in Birmingham, a city with lower sulphur dioxide levels than Barcelona. ${ }^{13}$ In addition, most controlled chamber studies have consistently shown that asthmatics are more sensitive to sulphur dioxide than healthy subjects.

With respect to ozone, few studies have assessed the effect on asthma admissions ${ }^{141617}$ and only one has reported a positive association. ${ }^{16}$ Other epidemiological studies have consistently reported transient decrements in lung function parameters in both healthy and asthmatic populations. ${ }^{40}$ The possibility of a causal relationship between ozone levels and respiratory effects has been based on experimental studies which have proposed both a direct inflammatory effect leading to increasing hyperreactivity ${ }^{41}$ and enhanced airways reactivity to inhalation of allergens. ${ }^{42}$ As in the case of sulphur dioxide, the reasons why we have not found an association in our study are undetermined.

Since concentrations of air pollutants in our study data were significantly correlated, the effect of each pollutant was assessed in separate models which makes the interpretation of the results more difficult. Thus, nitrogen dioxide could be a marker of the exposure to other air pollutants, particularly black smoke, which 
could lead to a confounded association. However, when nitrogen dioxide and black smoke were considered together in the regression analysis, the effect of both pollutants remained nearly the same in both seasons. On the other hand, the lack of association for combinations of pollutants may be explained by the inability of the statistical methods to deal with collinear variables. Experimental studies are probably more adequate than the observational setting to assess the effect of combinations of air pollutants. Another limitation of our analysis is that exposure to air pollutants was assessed at stations monitoring outdoor concentrations, but personal exposure to some pollutants such as nitrogen dioxide also occurs indoors at levels sometimes higher than those found outdoors. ${ }^{43}$ Misclassification of exposure could occur if the ratio of indoor to outdoor exposure to specific pollutants were to vary with time. This ratio depends on many factors including temperature and personal activity patterns. One of the advantages of stratifying the analysis by season is that the variability of the indoor to outdoor ratio is probably small during a given season. In addition, in Barcelona traffic density on working days shows little variability during the year, ${ }^{27}$ suggesting a steady emission of vehicle exhausts which is the main source of nitrogen dioxide in the city. Also, the temperate climate of Barcelona for most of the winter probably results in a similar pattern of exposure of the population to outdoor nitrogen dioxide as during the summer, which would explain the similar effect found in both seasons.

This study was supported by grant $90-676$ from the Fondo Investigaciones Sanitarias.

1 Woolcock AJ. Worldwide trends in asthma morbidity and mortality. Explanation of trends. Bull Int Union Tuberc Lung Dis 1991;66:85-9.

2 Magnussen $H$, Jörres R, Wagner $H M$, von Nieding G Relationship between the airway response to inhaled sulfur dioxide, isocapnic hyperventilation, and histamine in asthmatic subjects. Int Arch Occup Envirn Health 1990;62: 485-91.

3 Orehek J, Massari JP, Gayard P, Grimaud C, Charpin J Effect of short term, low-level nitrogen dioxide exposur on bronchial sensitivity of asthmatic patients. $f$ Clin Invest 1976;57:301-7.

4 Jörres R, Magnussen H. Airways response of asthmatics after a 30 min exposure, at resting ventilation, to $0.25 \mathrm{ppm}$ $\mathrm{NO}_{2}$ or $0.5 \mathrm{ppm} \mathrm{SO}_{2}$. Eur Respir f 1990;3:132-7.

5 Kreit JW, Gross KB, Moore TB, Lorenzen TJ, D'Arcy J, Eschenbacher WL. Ozone-induced changes in pulmonary function and bronchial responsiveness in asthmatics. $f$ Appl Physiol 1989;66:217-22.

6 Whittemore AS, Korn EL. Asthma and air pollution in the Los Angeles area. Am $\mathcal{F}$ Public Health 1980;70:687-96.

7 Perry GB, Chai H, Dickey DW, Jones RH, Kinsman RA Morrill CG, et al. Effects of particulate air pollution on Morrill CG, et al. Effects of particulate air poll
asthmatics. Am $\Im$ Public Health 1983;73:50-6.

8 Pope CA, Dockery DW. Acute health effects of $\mathrm{PM}_{10}$ pollution on symptomatic and asymptomatic children. $A m$ Rev Respir Dis 1992;145:1123-8.

9 Pope CA III, Dockery DW, Spengler JD, Raizenne ME. Respiratory health and $\mathbf{P M}_{10}$ pollution: a daily time serie analysis. Am Rev Respir Dis 1991;144:668-74.

10 Braun-Fahrlander C, Ackermann-Liebrich U, Schwartz J, Gnehm HP, Rutishauser M, Wanner HU. Air pollution and respiratory symptoms in pre-school children. $A m R e v$ Respir Dis 1992;145:42-7.

11 Schwartz J, Zeger S. Passive smoking, air pollution, and acute respiratory symptoms in a diary study of student nurses. Am Rev Respir Dis 1990;141:62-7.

12 Schwartz J. Air pollution and the duration of acute respiratory symptoms. Arch Environ Health 1992;47:116-22.

13 Walters S, Griffiths RK, Ayres JG. Temporal association between hospital admissions for asthma in Birmingham 1994;49:133-40.

14 Schwartz J, Slater D, Larson TV, Pierson WE, Koenig JQ Particulate air pollution and hospital emergency room varticulate air pollution and hospital emergency room 826-31.
15 Pope CA III. Respiratory hospital admissions associated with $\mathrm{PM}_{10}$ pollution in Utah, Salt Lake, and Cache Valleys. Arch Environ Health 1991;46:90-7.

16 Bates DV, Sizto R. Air pollution and hospital admissions in Southern Ontario: the acid summer haze effect. Environ Res 1987;43:317-31.

17 Bates DV, Baker-Anderson M, Sizto R. Asthma attack periodicity: a study of hospital emergency visits in Vancouver. Environ Res 1990;51:51-70.

18 Goldstein IF, Weinstein AL. Air pollution and asthma: effects of exposure to short term sulfur dioxide peaks. Environ Res 1986;40:332-45.

19 Antó JM, Sunyer J, Rodriguez-Roisin R, Suarez-Cervera $M$, Vazquez $\mathrm{L}$, and the Toxiepidemiological Committee. Community outbreaks of asthma associated with inhalation of soybean dust. $N$ Engl f Med 1989;320:1097102.

20 Martinez F, Sunyer J, Antó JM. Reliability of a monitoring system for respiratory emergency room admissions. Eur Respir $\mathcal{F} 1993 ; 6: 337-41$.

21 Sunyer J, Antó JM, Murillo C, Sáez M. Effects of urban air pollution on emergency room admissions for chronic air pollution on emergency room admissions for chronic obstructive

22 Sunyer J, Sáez M, Murillo C, Castellsague J, Martínez F, Antó JM. Air pollution and emergency room admissions for chronic obstructive pulmonary disease: a 5-year study. Am $\mathcal{F}$ Epidemiol 1993;137:701-5.

23 Dosman JA, Hodgson WC, Cockcroft DW. Effect of cold air on the bronchial response to inhaled histamine in patients with asthma. Am Rev Respir Dis 1991;144:45-50.

24 Linn WS, Shamoo DA, Anderson KR, Whynot JD, Avol EL, Hackney JD. Effects of heat and humidity on the responses of exercising asthmatics to sulfur dioxide exposure. Am Rev Respir Dis 1985;131:221-5.

25 Liang KY, Zeger SL. Longitudinal data analysis using generalised linear models. Biometrika 1986;73:13-22.

26 McCullagh P, Nelder JA. Generalised linear models. London: Chapman and Hall, 1983.

27 Aceves M, Grimalt JO. Seasonally dependent size distributions of aliphatic and polycyclic aromatic hydrocarbons in urban aerosols from densely populated areas. Environ Sci Technol 1993;27:2896-908.

28 Aceves M, Grimalt JO. Large and small particle size screening of organic compounds in urban air. Atmos Environ 1993;27B:251-63

29 Vedal S, Schenker MB, Muñoz A, Samet JM, Batterman $S$, Speizer FE. Daily air pollution effects on children's respiratory symptoms and peak expiratory flow. $A m \mathcal{F}$ respiratory symptoms and peal
Public Health 1987;77:694-8.

30 Roemer W, Hoek G, Brunekreef B. Effect of winter ambient air pollution on respiratory health of children with chronic respiratory symptoms. Am Rev Respir Dis 1993;147:118 24

31 Hazucha MJ, Ginsberg JF, McDonnell WF, Haak Jr ED, Pimmel RL, Salaam SA, et al. Effects of $0 \cdot 1 \mathrm{ppm}$ nitrogen dioxide on airways of normal and asthmatic subjects. $\mathcal{f}$ Appl Physiol 1983;54:730-9.

32 Bylin G, Londwall T, Rehn T, Sundin B. Effects of short term exposure to ambient nitrogen concentrations on human bronchial reactivity and lung function. Eur $\mathcal{F}$ Respir Dis $1985 ; 66: 205-17$.

33 Linn WS, Solomon JC, Trim SC, Spier CE, Shamoo DA Venet TG, et al. Effects of exposure to $4 \mathrm{ppm}$ nitrogen dioxide in healthy and asthmatic volunteers. Arch Envirn Health 1985;40:234-9.

34 Kleinmann MT, Bailey RM, Linn WS, Anderson KR, Whynst JD, Shamoo DA, et al. Effects of $0.2 \mathrm{ppm}$ nitrogen dioxide on pulmonary function and response to bronchoprovocation in asthmatics. $\mathcal{F}$ Toxicol Environ Health 1983 12:815-26.

35 Bauer MA, Utell MJ, Morrow PE, Speers DM, Gibb FR. Inhalation of $0.3 \mathrm{ppm}$ nitrogen dioxide potentiates exercise-induced bronchospasm in asthmatics. Am Rev Respir Dis 1986;120:3-8.

36 Devalia JL, Sapsford RJ, Cundell DR, Rusznak C, Campbell AM, Davies RJ. Human bronchial epithelial cell dysfunction following in vitro exposure to nitrogen dioxide. Eur Respir $\mathcal{F} 1993 ; 6: 1308-16$.

37 Morrow PE. Toxicological data on $\mathrm{NO}_{2}$ : an overview. $f$ Toxicol Environ Health 1984;13:205-7.

38 Devalia JL, Rusznak C, Herdman MJ, Trigg CJ, Tarraf $\mathrm{H}$ Davies RJ. Effect of nitrogen dioxide and sulfur dioxide on airway response of mild asthmatic patients to allergen inhalation. Lancet 1994;344:1668-71.

39 Tunnicliffe WS, Burge PS, Ayres JG. Effect of domestic concentrations of nitrogen dioxide on airway responses to inhaled allergen in asthmatic patients. Lancet 1994;344: 1733-6.

40 Kinney PL, Ware JH, Spengler JD. A critical evaluation of acute ozone epidemiology results. Arch Environ Health 1988;43:168-73.

41 Aris RM, Christian D, Herarne PO, Kerr K, Finkbeiner WE, Balmes JR. Ozone induced airway inflammation in human subjects as determined by airway lavage and biopsy. Am Rev Respir Dis 1993;148:1363-72.

42 Molfino NA, Wright SC, Katz I, Tarlo S, Silvermann F, McClean PA, et al. Effect of low concentrations of ozone on inhaled allergen responses in asthmatic subjects. Lancet on inhaled allergen resp

43 Noy D, Brunekreef B, Boleu JSM, Houthuus D, de Koning $R$. The assessment of personal exposure to nitrogen dioxide in epidemiological studies. Atmos Environ 1990;24A: 2903-9. 